\title{
Research on Adjustments for Changes in the Contract Price of Variations under the EPC Mode
}

\section{— Based on the Conditions of Contractfor EPC/Turnkey Projects}

\author{
Ningyong Wen
}

Technical economy and management, Tianjin University of Technology, Tianjin, 300384, China

Email: 914421158@qq.com

Keywords: EPC model Engineering change, Contract price adjustment, Engineering procurement construction (EPC) / Turnkey Project Contract Conditions

\begin{abstract}
With the development of China's economy, many foreign contract models have been introduced into China and developed rapidly, such as the EPC model. As a typical model, EPC model integrates design, procurement and construction with EPC model. It has the characteristics of long construction cycle and complex construction. Compared with the DBB model, the contractor will bear more risks in the EPC modelm, such as engineering change, and then cause the adjustment of the contract price to the owner or general contractor benefit damage. Thus, how to avoid these problems reasonably is a hotspot, and the main research content.
\end{abstract}

\section{Introduction}

In recent years, EPC mode has been universally welcomed that some developed countries explored step by step according to market demand, gradually evolved to develop a package model. Abroad, theorists have always regarded the EPC model as a branch of the design-build (DB model) mode, and its literature has rarely been studied [1]. In 1999, the International Federation of Consulting Engineers recognized the fundamental difference between this model and design-build model and its broad application prospects, FIDIC prepared "Design Procurement Construction (EPC) / Turnkey Contract Conditions", thus confirming the independence of this model in the project contracting mode system. There are few researches on contract price adjustment caused by engineering changes under EPC mode. The 99th edition of FIDIC "Design Procurement and Construction (EPC) / Turnkey Contract Conditions" stipulates and studies the determination of engineering changes, however, rare in-depth and meticulous research, in this article, discussed the significance of its research, and strive to achieve a win-win situation for EPC owners and contractors.

The development time of foreign EPC mode is not very long, and the contract terms and documents were promulgated more intensively in 1995. It is an important period for EPC general contracting mode to make its system more perfect and promote EPC mode The EPC contract / turnkey contract condition promulgated in 1999 has been in use ever since and has a more important status in the general contracting mode. It is also an important part of many EPC general contracting modes This essay also based on the 1999 edition of EPC / Turnkey Contract Conditions to analyze the problem of price adjustment caused by the change of EPC general contract mode.

In the 1999 edition of EPC / Turnkey Contract Conditions, the definition of engineering change right under EPC mode was put forward. The scope of change right was greatly reduced compared with the Model Version of the 13th Contract Model. Under EPC / Turnkey Contract Conditions, the change states: "At any time prior to the issuance of a project acceptance certificate, an engineer may make changes by issuing instructions or requiring the contractor to submit a proposal." The change does not Should include the deletion of any work to be done for the surrender of others. " The owners of different responsibilities or external conditions caused by different contract prices are not the same, may lead to loss of general contractor interests. Therefore, another research topic in this paper is the division of responsibilities that lead to contract price adjustment caused by the change 
of project alteration to fill the deficiencies of the contract price adjustment document for the contractor.

\section{EPC model engineering change inducement analysis}

In the actual management of EPC projects, there are many reasons for the EPC project changes. In the implementation of EPC contract, the owner assumes responsibility for its own reasons, such as the project's objectives, functional requirements and design standards, as well as the legal changes and risks posed by force majeure. According to the 2011 version of "Construction Project Contract Contract Model Text (Trial)" in the thirteenth changes and the contract price adjustment requirements, the scope of the changes include design changes, changes in procurement, construction changes, outsourcing workers rush instructions, Adjust some projects and other changes. This chapter will focus on the above categories as an entry point and analyze the reasons for the changes.

\subsection{EPC mode design-induced changes}

It can be seen from the "Construction Project EPC Contract Model Text (for Trial Implementation)" that the main manifestation of the design change is to make corresponding changes to the process flow, layout and functions without changing the overall scale or the contractual stipulations Adjustments or changes in laws, regulations or standards promulgated after the implementation of the base date. Such changes can be considered as engineering design. The next section will provide a detailed analysis of the causes of these changes.

In the actual project management, the reasons for the design change is also varied. To sum up, there are roughly the following: First, due to changes in the quality of the work of the design agency; Second, due to the Employer's temporary changes to the design requirements caused by the change; Third, the Employer outsourced design, Confusion caused by the design changes. Such as Wen Kan, geological exploration is wrong, etc.; Fourth, the contractor agreed to the use of special construction materials and so on; Fifth, the scene in the construction of the same situation, we must adopt a new construction method; Sixth, the impact of natural disasters [2]. In the project management practice, due to design changes caused by changes in the visa about $80 \%$, is also the focus of attention.

Project design has a great impact on the project cost. To control the project cost, the most important thing is to design a good project and find the main reasons that lead to the project design change, so as to solve it in a targeted manner [3].

\subsection{Procurement triggered project changes}

Analysis of the status quo of China's project procurement, we can find there are still many imperfections and irregularities in the project procurement system, which is also the main reason for the change of procurement caused by the project. The following is the reason for the change of procurement caused by the project Analysis and summary of the Ministry of Water Resources in the government unit directly under the ten years as an example [4].

The reasons for the change caused by the procurement of the project procurement workers are summarized as follows:

\subsubsection{Have not established a coordinated and supporting project procurement regulations}

On the procurement of laws and regulations, generally speaking, the provisions of the more complete, but general, policy guidance too much content, the specific operational level of the provisions of less, some still need to continue to improve. And because of the procurement has strong practicality and strict procedural, procurement and other laws, regulations, rules and especially the "bidding law" between the convergence and coordination is particularly important, however, the current situation. This convergence and coordination is not satisfactory, which is one of the reasons for the change of procurement led to the project. 


\subsubsection{Local protectionism is serious; it is difficult to form a national big market}

At present, the industrial division and regional protection of the government procurement market in our country is very serious, and discrimination against suppliers often occurs. In some places, such problems as non-normative operations such as "black-box operations" still exist even through exclusion of other suppliers through local blockades and departmental monopolies.

\subsubsection{The risk of project procurement}

Procurement Procurement is the process of purchasing the required equipment, materials and other materials according to the needs of the project, including the sub processes of acquisition, purchase, logistics, quality assurance and contract management. Procurement span longer, generally throughout the entire project life cycle. The project procurement risk, generally refers to the procurement of man-made, economic and natural risks, such as procurement forecast deviations, can not meet the production requirements, or lead to exceed the budget.

To sum up, we have not yet established a coordinated and supporting project procurement rules and regulations system. Local protectionism is so serious that it is difficult to form a large national market. The risk of project procurement is one of the major causes of engineering procurement changes.

\subsection{Require early completion of the project caused by the change}

At this stage, China's engineering by the owners require the completion of the project ahead of time lead to changes in the status quo, less research on this regard, on the owners require completion ahead of schedule there are still many imperfections and irregularities, which is it caused the EPC After the project is changed in mode, the price adjustment is difficult to determine one of the main reasons.

First of all, the definition of the owner's requirement for early completion is first defined. When the owner requests early completion and the non-general contractor's own reasons are lagging behind, the requirements will be completed ahead of time and completed early. For the general contractor, it is A form of rush work.

The rush to work in the definition of project management: the cost and progress of the trade-offs, to determine as little as possible to increase the cost of the project to minimize the time required. Progress is not always able to produce a viable option, but often increase costs. Rush has the following characteristics: During the implementation of the project, rush to work belongs to the category of progress control; rush to work will result in increased manpower and equipment investment so that the expenditure of the project will be increased to some extent; in order to rush to work, parallel work may bring about a Series of claims for changes [5].

It can be seen that the reasons for the early completion are the following: Due to possible geological disasters, the owner demanded completion ahead of time (for example, the upcoming Yellow River flood season will affect the construction and other reasons); in order to catch up with the delay due to geological disasters, the owners Instructions to rush.

\subsection{Owners require changes in the contents of the project}

The improvement of engineering standards proposed by the proprietor is one of the inducing factors of project change, which is caused by the adjustment of factors such as the level of material used, the optimization of engineering structure, the optimization of specifications, or the optimization of installation location. But with these three changes at the same time is the construction machinery and construction personnel changes.

\subsubsection{The owner asks for improvement of engineering standards}

According to the characteristics of the project divided into three categories: 1) application materials; 2) engineering structure; 3) specifications, installation location.

Therefore, the specific performance improvement for the project is divided into three categories according to these three categories: 1 ) the use of materials to improve the level; 2) the optimization 
of the structure of the project; 3) the optimization of the specifications or the installation location optimization changes.

\subsubsection{Improve the standard trigger measures to change the project}

Measures are divided into the unit price calculation measures and the total price of the project measures, and owners raised the standard demand arising from the price adjustment is for the unit price of the measure items.

These actual needs during the entire construction and operation period are derived as the project progresses and can not be reasonably foreseen from the outset. This is also the reason that property owners are asking for higher standards and the inducement for project changes.

\subsection{Other factors caused by the project changes}

At present, there are few theoretical bases for engineering changes caused by other factors in the general contracting mode. The provisions of EPC Contract / Turnkey Contract Conditions are not very clear either. According to the 2011 Construction Project Project general contract contract model text (for Trial Implementation) "were summarized, including: force majeure; unforeseen events; labor disputes; engineering laws and regulations of the country; environmental reasons.

The general contracting mode causes many reasons for the engineering change, but other reasons can not be avoided in advance. For this reason, the engineering changes under the EPC mode can be made under the coordination of both parties A certain price adjustment measures to make up for the loss of the damaged party in order to achieve rationalization of the progress of the project and the mode of cooperation.

\section{EPC price management change risk analysis}

\subsection{Changes in EPC mode do not include contractors to correct their various defects}

In EPC mode, the Employer has the permission to approve the change. The Employer shall have the power to issue the Order of Change based on the recommendation of the Supervisor, the proposal of the Contractor and the scope of the change agreed upon by the Contracting Party at any time after the contract is effective and before completion of the project. The change order is sent in writing. The written order of change approved by the Employer and issued by the Employer is a change. Including the Employer issued a change order directly or by the Employer approved by the supervisor issued a change order. The contractor is obliged to submit written change proposals to the Employer at any time, including shortening the construction period, reducing the contractor's cost of engineering, construction, maintenance and operation, increasing the efficiency or value of the Completion Project, long-term benefits to the Employer and other interests. Upon receiving such advice, the Employer shall send a written notice not to adopt, adopt or supplement further information. It should be noted that the contractor shall correct, adjust and improve at his own expense, without any alteration, his own defects in the design, procurement, construction, completion test and post-completion test.

\subsection{EPC mode changes in the program list and price determination}

Changes in the EPC model include changes in design, procurement changes, construction changes, outsourcing hiring instructions, conditions of some projects and special provisions of the other changes agreed. As shown in the table 1, a list of procedures for the EPC general contracting project change is summarized in the implementation of the EPC project. The general contractor can compare the reasons for the changes one by one according to the table and change the procedures so as to reasonably determine the construction price.

EPC general contracting project change program list, attention should be paid to change the program. As EPC EPC contractors are generally design institutes with strong design capabilities or consortia of design consulting firms and engineering companies and the owners hope to divert most of their risks through this contracting, the general contractor will take greater risks Under the general contracting EPC project mode, the general contractor not only has to bear the design risk, 
but also need to take risks that can not be forecasted and can not be effectively prevented by the natural forces. In the traditional mode, and at the same time, such risks are more common. If they happen, they will result in the delay of the construction period and the increase of the cost. Under the traditional mode, the right of claiming by the contractor will no longer exist in EPC general contracting mode. All of this no doubt greatly increased the general contractor in the project implementation process of the risk. It is necessary to seize all the conditions that may cause changes to make changes to the project through accurate changes to avoid the loss of the general contractor.

Table 1 EPC general contracting project change procedures list

\begin{tabular}{|c|c|c|}
\hline Category & Content & $\begin{array}{c}\text { Project Change Approval } \\
\text { Process }\end{array}$ \\
\hline & $\begin{array}{l}\text { 1. The adjustment of the production process; however, the } \\
\text { production route and scale approved by the preliminary } \\
\text { design have not been expanded or reduced or the production } \\
\text { line and scale as stipulated in the contract have not been } \\
\text { expanded or reduced; } \\
\text { 2. The layout of the layout, vertical layout, the use of local } \\
\text { functions of the adjustment; but did not expand the } \\
\text { preliminary design approval of the building scale, did not } \\
\text { change the use of preliminary design approval function; or } \\
\text { did not expand the contract the size of the building, the } \\
\text { contract has not changed the use of Features; } \\
\text { 3. Supporting the engineering system of the process of } \\
\text { adjustment, the use of functional adjustments; } \\
\text { 4. Adjustment of benchmark control points, benchmark } \\
\text { elevation and baseline in the region; } \\
\text { 5. The equipment, materials, components of the } \\
\text { performance, specifications and the number of adjustments; } \\
\text { 6. Changes due to newly promulgated laws, standards and } \\
\text { norms after the implementation of the base date; } \\
\text { 7. Other design issues beyond the contract; } \\
\text { 8. Additional work required for the above changes. }\end{array}$ & $\begin{array}{l}\text { 1. The Employer changes: } \\
\text { Normal change procedure: } \\
\text { The Employer notifies the } \\
\text { Contractor in writing } \\
\text { Subcontractor submits } \\
\text { written proposal report } \rightarrow \text { The } \\
\text { Employer reviews the } \\
\text { Proposal Report and issues a } \\
\text { written notice of approval, } \\
\text { cancellation, change and } \\
\text { further request. } \\
\text { Emergency } \\
\text { Procedure: } \\
\text { The Employer sends an urgent } \\
\text { change order in writing or } \\
\text { verbally. } \rightarrow \text { The Contractor } \\
\text { executes the Order }\end{array}$ \\
\hline & $\begin{array}{l}\text { 1. The Contractor has signed the procurement contract with } \\
\text { the relevant supplier or has commenced the manufacturing, } \\
\text { supply, transportation and so on according to the list } \\
\text { approved by the Employer, and the Employer informs the } \\
\text { Contractor to choose another supplier in the list; } \\
\text { 2. Changes due to newly enacted laws, standards and norms } \\
\text { after the implementation of the base date; } \\
\text { 3. The Employer requests to change the location of } \\
\text { inspection, inspection, testing and testing and additional } \\
\text { testing; } \\
\text { 4. Employer requirements increase or decrease the } \\
\text { contracted spare parts, special tools, after the completion of } \\
\text { the procurement of test materials; } \\
\text { 5. Additional work required for the above changes. }\end{array}$ & $\begin{array}{l}\text { immediately after receiving } \\
\text { the order. (In case the } \\
\text { Employer issues an urgent } \\
\text { change order verbally, the } \\
\text { change must be confirmed in } \\
\text { writing within } 48 \text { hours. } \\
\text { Subcontractor } \\
\text { manager) } \\
\text { 2. The Contractor exercises } \\
\text { the right of change suggestion: } \\
\text { The contractor proposes a } \\
\text { written change } \rightarrow \text { the } \\
\text { Employer sends a written }\end{array}$ \\
\hline $\begin{array}{l}\text { Construction } \\
\text { changes }\end{array}$ & $\begin{array}{l}\text { 1. According to the above design changes, resulting in } \\
\text { changes in construction methods, equipment, materials, } \\
\text { components, labor and engineering changes; } \\
\text { 2. The outsourcer requires additional testing to change the } \\
\text { test site; } \\
\text { 3. In accordance with sub-paragraph 5.2.1 (1) and (2), newly } \\
\text { added construction obstruction handling; } \\
\text { 4. The Employer shall notify the completion of the } \\
\text { completion test if the Employer has accepted the acceptance } \\
\text { test of the completed test or deemed to have passed the } \\
\text { acceptance test. } \\
\text { 5. Changes due to newly enacted laws, standards and norms } \\
\text { after the implementation of the base date. } \\
\text { Other on-site visas } \\
\text { 7. Additional work required for the above change. }\end{array}$ & $\begin{array}{l}\text { notice that no further } \\
\text { information is accepted, } \\
\text { adopted or supplemented } \\
\text { Note: Contractor's own } \\
\text { design, procurement, } \\
\text { construction, completion test, } \\
\text { after the completion of the test } \\
\text { defects, should be at their own } \\
\text { expense to amend, adjust and } \\
\text { improve, does not belong to } \\
\text { the change. }\end{array}$ \\
\hline
\end{tabular}




\section{EPC model project changes caused by contract price adjustments}

\subsection{Project to determine the amount}

In the EPC general contracting mode, the adjustment of the contract price requires the following steps. Firstly, the quantity of the changed engineering quantity should be quantitatively determined. In the previous chapter, the qualitative analysis of the engineering quantity has been made. The section will not repeat them, this section mainly to change the engineering formula and calculation methods to do a more detailed description of the following section to give a list of quotas set a pawn for the next step to adjust the contract price to do Basis, the second step is the need to apply the fixed unit price, according to the different regions of the quota, to carry out the contract price of the combination, price. The third step, the preparation of materials analysis table, the fourth step, the cost of calculation, the fifth step, the review, the above is complete price adjustment steps, this section describes the second step, detailed EPC mode changes in the amount of the project to determine See Appendix.

\subsection{Bill-based quotes}

Fixed pricing is based on the budget quota divided into a number of sub-items, bottom-up gradually by the level of the final summary summing up the sum of the calculation of the project volume, according to the relevant government departments issued a fixed budget unit price of resources And calculate the amount of engineering to determine the project direct costs, overheads and other related costs of the project, the relevant departments in charge of rules and regulations shall be based on fees and ultimately obtained, and finally add a reasonable estimate The unforeseen expenses due to the existence of uncertain risks and the material adjustment factors are summarized as the project budget.

\subsection{Floating rate adjustment}

In recent years, with the continuous development of EPC projects in China and the constant improvement of EPC projects in China, the contract prices in EPC projects have also been clearly stipulated and required. However, for EPC EPC projects in terms of engineering, for the principle of establishing a fair and mutually beneficial contract, it is necessary to make some adjustments to the downward float rate stipulated in the contract. However, at present, there is no clear adjustment plan in China. In this paper, an example is the method of adjusting the downward float rate in the contract of the general contracting project that needs the government approval, which analyzes and models the general contracting mode to adjust the price, that is how the contractor should compensate the contractor so that the general contractor can successfully complete the project.

Price float rate for the tender offer, is quoted quota quota, the tender unit promised to float at a fixed rate fixed rate. The use of floating rate, the bidder can let the developer to a certain percentage, but also to enhance the competitiveness of their tender offer. Among them, the bid under the float rate that the bidder quoted the floating rate.

\section{EPC model changes caused by the project price adjustment other ways to solve}

\subsection{Actively use negotiation to solve price adjustment}

In the event of alteration during the construction process and consequential loss to the contractor, in order to ensure the smooth progress of the project and the harmonious relationship between the contractor and the contractor, the contractor shall actively use negotiation to resolve such disputes. At the same time, as an effective way to resolve disputes, the transaction cost of negotiation is the lowest compared with other processing methods. Therefore, the use of negotiation to resolve price disputes is beneficial to both parties.

Negotiation as a solution to disputes between the two sides price dispute is the most effective, most economical and easiest way. When disputes occur between contracting parties and contracting parties, both parties shall be encouraged to solve the dispute through negotiation. Negotiation is a more complicated process and requires the contracting parties to reach a consensus after repeated 
negotiations. Therefore, during the whole process of consultation, the contracting parties should adhere firmly to the above considerations so as to facilitate the smooth progress of the consultation so as to ensure the ultimate satisfactory outcome of both parties.

\subsection{Reference to the principle of change of situation to apply for arbitration or litigation}

When a price dispute arising from a project alteration under a price contract event happens, it is difficult for both parties to reach a common opinion. Even if both parties can not resolve the dispute by negotiation, they may take the form of litigation or arbitration in the court, Way to take advantage of the principle of change.

In 2009, the State promulgated the "Judicial Interpretation of Contract Law (II)", of which Article 26 stipulates the applicability of the change of circumstances. When the contract is signed, if there is an event of non-commercial risk caused by unforeseeable circumstances and force majeure, the two parties or parties to the contract will cause obvious losses if they continue to perform their contractual obligations. After the parties have lodged a contract with the court to lift the contract, the court According to the situation be approved.

Through the above analysis of the terms available: (1) non-force majeure; (2) non-commercial risk; (3) unpredictability. This is an event applicable to the principle of change of circumstances, which should have three preconditions. The existence of these conditions specifically stipulates the scope of application of the principle of change of circumstances.

At this stage, there are still some problems that are hard to be accurately judged and quantified in the actual application due to the principle of change of circumstances. Therefore, the principle of change of circumstances should be fully integrated with the discretion of judicial personnel to play their due role. Moreover, some local courts have already settled some disputes through reference to the principle of change of circumstances. This provides the case support for better application and promotion of the principle of change of circumstances. In order to better apply the principle of change of circumstance in order to maintain the substantive fairness of the contract, the state should formulate supplementary regulations to further improve the standards applicable to the principle of change of circumstances. This helps to prevent the principle of change of circumstances being over-quoted during the litigation process and plays an important role in safeguarding the seriousness of the law.

\section{Conclusions}

At present, the EPC project general contracting model occupies a higher and higher proportion both in the international market and in the domestic market. This article focuses on the project cost adjustment from the perspective of risk sharing in the EPC model, which leads to the contract price adjustment and reduces the engineering change Both sides risk avoiding conflicts and disputes. This article will EPC model under the perspective of risk sharing changes in the project, the first definition and incentive analysis, and then change the responsibility of engineering division, this method effectively analyzes the risk of project changes, contract price adjustments can reduce the increase caused by the owners Increased costs.

\section{References}

[1] Zhang Xueli. EPC project under the EPC project management [D]. Xi'an University of Architecture and Technology, 2008.

[2] Ai Guang fresh. Construction Engineering Change Contract Management [D]. Dongbei University of Finance and Economics, 2007.

[3] Zhou Meng. Research on Risk Control of Engineering Procurement [J]. Low Carbon World, 2015, (01): 149-150.

[4] An Guoxiang, Hu Tingting. A Study on the Procurement Change of Government Procurement - 
A Case Study of Ministry of Water Conservancy [J]. Chinese Journal of Accounting, 2016, (31): 49-50.

[5] Pei Pei, Liu Limin.Construction and management of construction projects in the rush and change [J]. Hydropower and Renewable Energy, 2013, (S2): 94-97. 